EGU2020-8721, updated on 15 Feb 2021

https://doi.org/10.5194/egusphere-egu2020-8721

EGU General Assembly 2020

(c) Author(s) 2021. This work is distributed under

the Creative Commons Attribution 4.0 License.

\title{
Lithosphere deformation due to tearing at STEPs: an analogue model approach
}

\author{
Taco Broerse ${ }^{1}$, Ernst Willingshofer ${ }^{1}$, Dimitrios Sokoutis ${ }^{1,2}$, and Rob Govers ${ }^{1}$ \\ ${ }^{1}$ Utrecht University, Faculty of Geosciences, Department of Earth Sciences, Utrecht, Netherlands (d.b.t.broerse@uu.nl) \\ ${ }^{2}$ University of Oslo, Department of Geosciences, Oslo, Norway
}

Tearing of the lithosphere at the lateral end of a subduction zone is a consequence of ongoing subduction. The location of active lithospheric tearing is known as a Subduction-Transform-EdgePropagator (STEP), and the tearing decouples the down going plate and the part of the plate that stays at the surface. STEPs can be found alongside many subduction zones, such as at the south Caribbean or the northern end of the Tonga trench. Here we investigate what controls the evolution and geometry of the lithospheric STEP. Furthermore we study the type of lithosphere deformation in the vicinity of STEPs.

We study the ductile tearing in the process of STEP evolution by physical analogue models, which are dynamically driven by the buoyancy of the subducting slab. In our experiments, the lithosphere as well as asthenosphere are viscoelastic media in a free subduction setup. A stressdependent rheology plays a major role in localization of strain in tearing processes of lithosphere such as slab break-off. Therefore we developed and tested analogue materials that can serve as mechanical analogues for the stress-dependent lithosphere rheology, such as has been inferred by rock laboratory test for dislocation creep of olivine.

We show the influence of age and integrated strength of the lithosphere and its contrasts across the passive margin, on the timing, depth, and the degree of localization of the tearing process. When tearing of the lithosphere is dominated by ductile deformation, we find that gradual necking of the passive margin precedes tearing. In many of our models we find that tearing at the lateral ends of the subduction zones is resisted by the lithospheric strength, such that tearing is delayed with respect to rollback of the slab. This has consequences for the shape of the subduction zone, and for the separation between the subducted slab and the surface lithosphere. We study the type of deformation in the vicinity of the STEP of the lithosphere that stays at the surface, and relate this to deformation observed beside STEP fault zones along the Hellenic slab, the Lesser Antilles slab, and the New Hebrides slab. 